www.ohsu.edu/xd/research/centers-institutes/oregon-instituteoccupational-health-sciences/outreach/or-face/

\title{
Crane operator killed by falling steel beam
}

\section{SUMMARY}

A 40-year old crane operator was killed when a 35 -foot $(5600 \mathrm{lb}) \mathrm{H}$-beam fell crushing the crane cab and striking him in the head. During a pile driving operation, the $\mathrm{H}$-beam pile had been placed in a drilled 25-foot hole. While using a vibratory hammer to force the pile further into the hole, the pile shifted. After several failed attempts to correctly position the pile it was extracted using the hydraulic clamp of the vibratory hammer and moved 12 feet from the hole. It was held in a vertical position with the bottom of the pile resting on the ground. The clamp holding the top of the pile unexpectedly released. The pile was not rigged to the clamp housing or attached to the whipline. The $5600 \mathrm{lb}$ pile fell, struck and crushed the crane cab, and killed the operator.

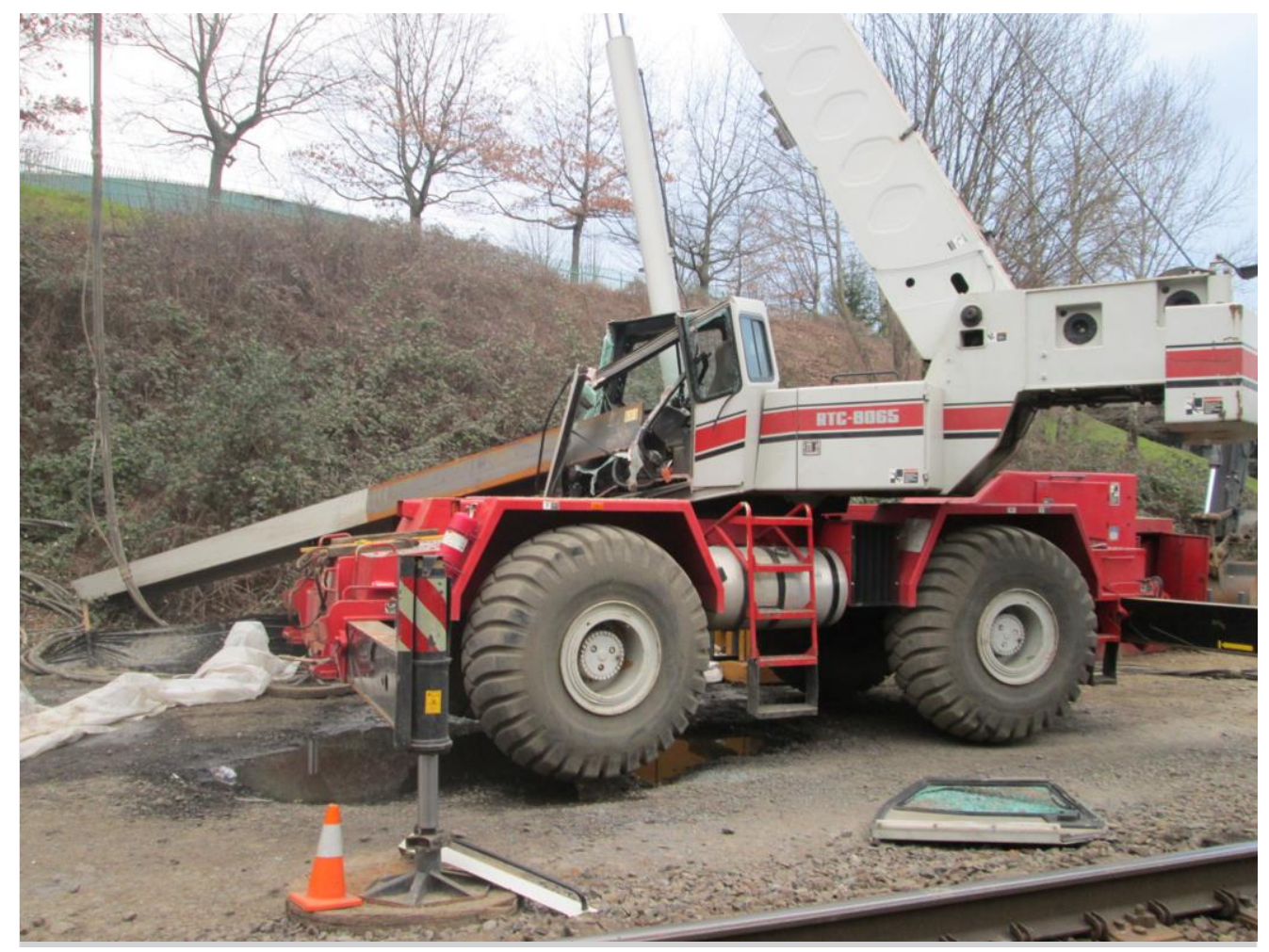

Figure1. Crane cab struck by H-beam. 


\section{RECOMMENDATIONS}

- Employers should ensure that pile driving operations include redundant measures (e.g., two switch safety feature, restraints) to prevent release of piles from lifting and pile driving equipment.

- Employers should consult the equipment manufacturer prior to modification or addition to equipment. The wireless remote control that replaced the original pendant control may have unexpectedly opened the clamp and released the pile.

- Employers should ensure that workers are trained on the hazards of equipment and follow manufacturer's operating manual (e.g., bleeding entrained air from the line to prevent clamp failure).

- Employers should ensure that a risk assessment is conducted whenever a change-in-plan occurs and workers should be encouraged and reinforced for reporting unsafe conditions and participating in implementation of hazard controls.

- Incident investigations should include a root cause analysis to identify hazards, recommended actions to control these hazards and follow-up procedures to ensure that these actions are implemented.

OR-FACE supports the prioritization of safety interventions using a hierarchy of safety controls, where top priorities are hazard elimination or substitution, followed by engineering controls, administrative controls (including training and work practices), and personal protective equipment.

\section{INTRODUCTION}

On February 17, 2015, a crane operator was struck in the head when an $\mathrm{H}$-beam pile that was held in a vertical position by a vibratory hammer clamp, fell, crushed the crane cab, and killed the operator. OR-FACE contacted OR-OSHA after hearing a local news report to confirm incident. OR-FACE completed the investigation report by obtaining the OR-OSHA field investigation documentation, medical examiner reports, police reports, and follow-up interviews with the OR-OSHA

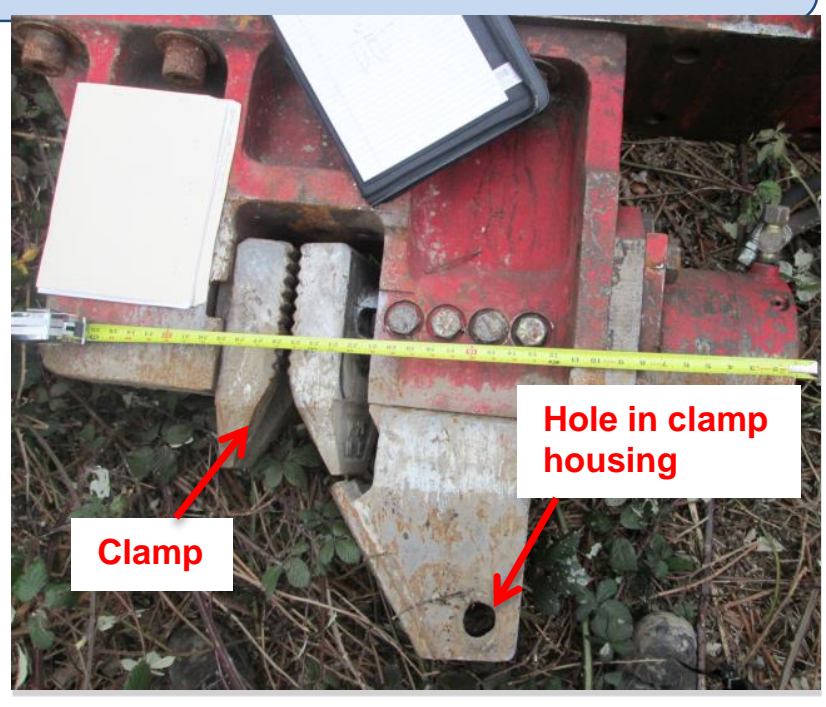

Figure 2. Close up of the vibratory hammer clamp housing. 
investigator and vibratory hammer manufacturer.

The employer, a company specializing in crane rental, rigging, pile driving and heavy hauling for nearly 13 years, was a subcontractor hired to install piles for a retaining wall being constructed along a section adjacent to the railroad tracks (railroad right-of-way). The company employed approximately 40 union workers. On the day of the incident, a six-person crew was assigned to the pile driving project.

A 35-foot, 5600-lb H-beam pile, was lifted and set vertically in a 25-foot newly drilled hole. The pile sank a few feet into the hole and was supported by the walls of the hole. A hydraulic vibratory hammer was then attached to the crane rigging and swung into place over the pile. Using a hand-held wireless remote control a hydraulic clamp on the base of the hammer was opened by the foreman and dropped over the pile then closed. The crane operator repositioned the pile while clamped onto the vibratory hammer. The foreman remotely started the vibrating action of the hammer to push the pile further down into the hole. The crew noticed that the pile shifted and was several inches off center. After several unsuccessful attempts to correctly position the pile, a decision was made to stop the vibratory hammer, completely extract the pile, and re-drill the hole. The pile, still attached to the vibratory hammer hydraulic clamp was lifted out of the hole and vertically positioned approximately 12 feet to the side of the hole.

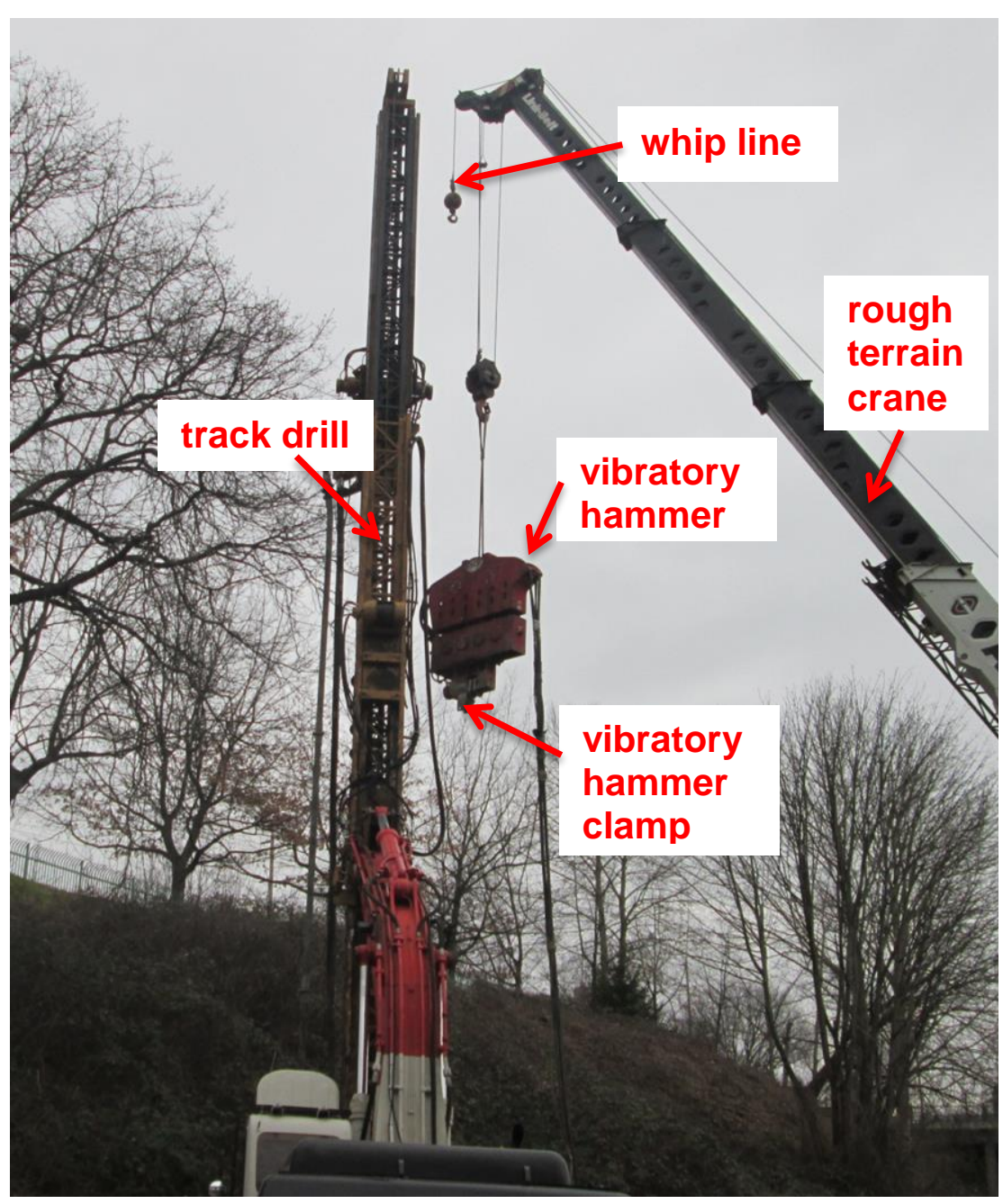

Figure 3. The equipment The bottom of the pile was resting on the ground with the clamp of the hammer holding it in a vertical position. A track drill was moved into position to re-drill. When re-drilling began 
the clamp holding the top of the pile unexpectedly failed releasing the pile which struck the crane cab and the operator.

The 40-year old crane operator had worked for the employer for three years and was a member of the local operating engineers union. He had completed training and was NCCCO (National Commission for the Certification of Crane Operators) certified to operate a telescopic boom crane-fixed cab (TSS) and telescopic boom crane-swing cab (TLL) in 2012. In the same year he completed an OSHA 10-hour class. In 2013, he completed the employer crane competency test.

The employer had a 160-page written safety program that included safety committee meetings, new employee orientation, personal protective equipment, safety audits and crane safety.

\section{INVESTIGATION}

The employer was contracted to install steel $\mathrm{H}$-beam piles as vertical structural members for a new retaining wall. A six person crew was assigned to the project. Work began at 6:45 am on February 17, 2015, with a safety meeting that included the crew, general contractor and customer.

A track drill was used to drill a hole, approximately 25 feet deep for placement of the first pile in the series. As the track drill extracted the auger from the hole, concrete was pumped through the center of the auger to stabilize the walls as the auger was extracted. Once the auger was extracted, the drill was backed away from the hole. Problems with the track drill delayed completion of the first hole until late morning.

The crane operator positioned a 65-ton Link-Belt Rough Terrain crane to pick up a 35-foot, $5600-\mathrm{lb}$ pile with a quick release coupler device attached to the lifting block of the crane and one end of the pile. The pile was moved, swung over and set vertically in the newly drilled hole and supported by the walls of the hole. The crane's rigging was then slacked and the pile was released by workers pulling release ropes attached to the quick coupler device.

A hydraulic vibratory model MKT V-17/HP-325 hammer (MKT Manufacturing Inc., St. Louis, $\mathrm{MO}$ ) was then attached to the crane rigging and swung into place over the pile. The vibratory hammer was built in 1979, and was powered by a diesel driven, hydraulic power unit with a 150-foot hydraulic hose bundle. It was originally operated through a control panel located on the power unit or remotely with a 50-foot electrical control pendant cable assembly. However, the employer had contracted a company to design and supply a wireless remote control (see Figure 4) to replace the pendant device. The design options for the remote control included an optional safety finger trigger that must be activated before any vibratory hammer action controls would function. However, this "safety trigger" (see Figure 5) option 
was not selected for the wireless remote control unit that was ultimately used during the incident.

The foreman using the handheld wireless remote control (see Figure 4) opened the clamp on the base of the hammer. The open clamp was dropped over the web of the H-beam pile then closed remotely. The crane operator repositioned the pile by lifting it while clamped to the vibratory hammer to straighten it while in the hole. The foreman then started the vibratory hammer using the remote control.

After vibrating the pile down into the hole, the crew noticed that the pile had shifted and was several inches off center. After several unsuccessful attempts to center the pile, the foreman stopped the vibratory hammer. He made the decision to extract the pile and redrill the hole before the concrete could set.

The project was behind schedule, it was late in the day, and concrete was beginning to set. These factors may have contributed to the decision to act quickly and forego a hazard assessment to ensure a safe lift for this last minute change in plan.

The pile was extracted while it was clamped to the vibratory hammer. The pile did not have a safety chain or line connecting it to the

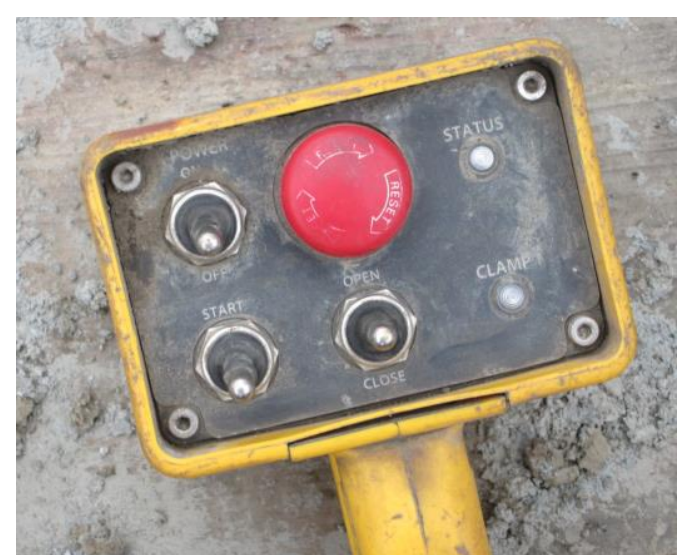

Figures 4 and 5. Vibratory hammer wireless remote control. Below is a drawing with the safety trigger option.

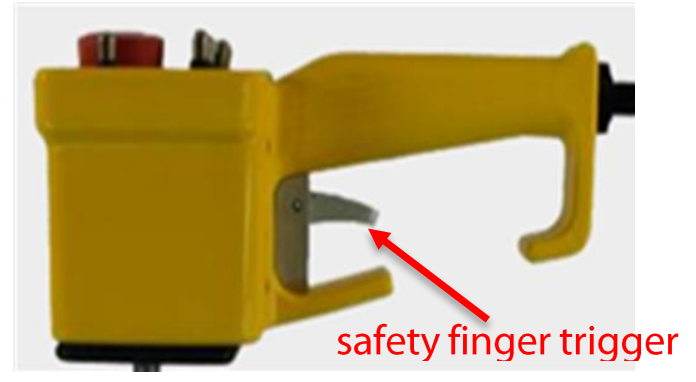
vibratory hammer housing nor was the crane's whip line attached to the pile. The pile was lowered approximately 12 feet away from the hole and set in a vertical position with the lower end resting on the ground. The track drill was then moved back into position and the crew began re-drilling. The crew worked within the fall zone of the pile. At approximately 5:30 pm the vibratory hammer clamp unexpectedly released the pile which fell, struck the crane cab and killed the operator.

Although the reason for release could not be determined, three possible scenarios were identified through investigation.

(1) Air could have entered the hydraulic system during the site assembly of the hydraulic power unit. Specific instructions in the manufacturer's Operation, Maintenance and Parts Manual (p. 12) states "Whenever the hydraulic lines of the system has been reconnected THE CLAMP CYLINDER CIRCUIT MUST BE BLED OF ENTRAINED AIR..... CAUTION: FAILURE TO 
COMPLETELY BLEED THE CLAMP CIRCUIT OF AIR MAY IMPAIR CLAMPING FORCE AND DAMAGE $J A W S$." When interviewed during the investigation, the crew was not aware of this requirement.

(2) The toggle switch on the wireless remote control (see Figure 4) may have been inadvertently activated by brushing against an object while hanging on the foreman's belt releasing the clamp on the vibratory hammer. For this investigation the vibratory hammer manufacturer was contacted to determine whether remote controls for vibratory hammers were available. A picture of their remote control was provided (see Figure 6) and the safety features they described included recessed buttons and two buttons, PTO and clamp or vibro, must pressed simultaneously to initiate action. This prevented inadvertent action when only one button is pressed. Whereas the remote control unit used in the incident had toggle switches extending beyond the case (See figures 4 and 5) and it did not include a safety trigger, a two switch safety feature, to prevent action of the vibratory hammer when the toggle switch was inadvertently pressed.

(3) Radio frequency interference with the $900 \mathrm{MHz}$ wireless remote control may have initiated clamp release. The incident occurred in the city where the site was surrounded by city streets, freeways, a convention center, and industrial area. Without testing or additional information, this scenario could not be ruled

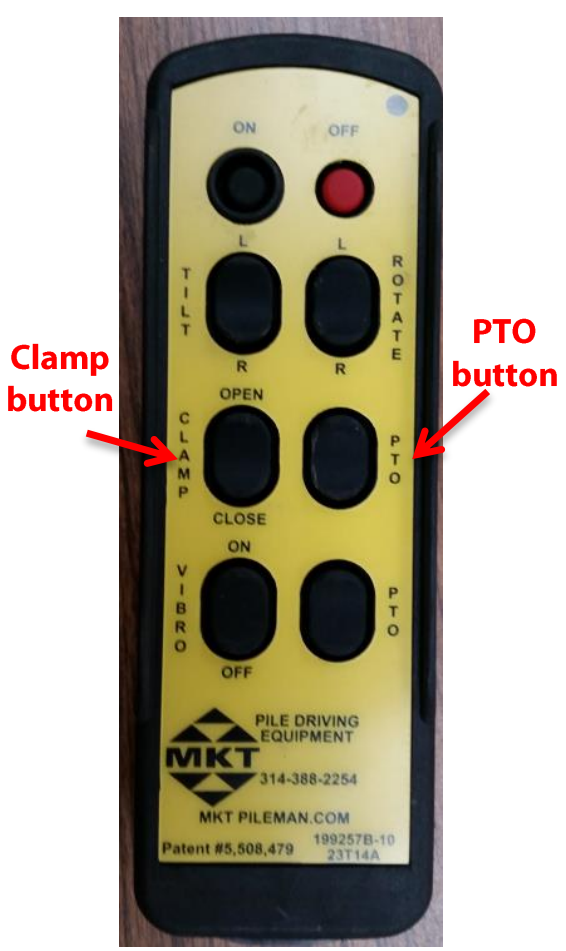

Figure 6. MKT remote control for a vibratory hammer out. Correspondence three months prior to the incident revealed problems with the remote control. Problems, although not described in the documents, were also reported during a previous job.

When the clamp inadvertently opened, the pile fell onto the crane cab. There was no line attached to the pile to restrain the fall as recommended by the manufacturer. The manufacturer's Operation, Maintenance and Parts Manual stated that, "pile extraction operations are frequently fitted with a shackle and a short line attached through the hole drilled in the pile clamp housing,.... and the shackle is fastened into the lifting hole in the pile." Figure 2 shows the hole in the pile clamp housing. In the same paragraph, the manual directs how to extract and store the pile, "The pile is then pulled out of the ground, and the hammer and pile swung to where the pile will be stacked. The lower end of the pile is set on the ground and the....hammer jaws are opened allowing the pile head to fall away from the jaws and hang by the line and shackle. The hammer and dangling pile are lowered to the ground where the shackle is disconnected from the pile." (MKT Operating, Maintenance \& Parts Manual, p.16) 
Other vibratory hammer manufacturer's emphasized, "pile handling/safety line should be used to attach the pile to the hammer should the clamps suddenly lose hydraulic pressure," (see ICE manual). APE (American Pile driving Equipment) listed in their rules and precautions, "attach whip line to pile when pulling".

Employer documents collected in the investigation revealed a similar event three years before this incident. No one was injured when a pile slipped out of the clamp, fell and damaged heavy equipment. The employer had documented the incident, determined that the clamp teeth were worn on one side and stated in their accident report, "vibe needs jaws make sure that we keep pile choker on pile."

\section{CAUSE OF DEATH: Blunt force head trauma}

\section{RECOMMENDATIONS/DISCUSSION}

Recommendation \#1: Employers should ensure that pile driving operations include redundant measures (e.g., two switch safety feature, restraints) to prevent release of piles from lifting and pile driving equipment.

- Attaching the pile to the whip line or with a wire rope to the clamp housing could have prevented the incident. In a CPWR report analyzing crane related deaths, "struck by crane loads" was the second leading cause of deaths (21\%). The major cause of "struck-by-load deaths was load came loose from rigging" (19\%).

- The investigation of the incident three years ago identified the potential for clamp failure. A redundant system to restrain the pile if the clamp failed should have been implemented and enforced for all pile driving projects.

\section{Recommendation \# 2: Employers should consult the equipment manufacturer prior to} modification or addition to equipment. The wireless remote control that replaced the original pendant control may have unexpectedly opened the clamp and released the pile.

- The replacement of the pendant control on the vibratory hammer for a wireless remote was a significant modification. The unexpected release of the pile by the vibratory hammer clamp may have been as a result of an inadvertent movement of the toggle switch or radio frequency interference. For critical and hazardous equipment, the manufacturer should be consulted before devices/equipment alterations or modifications occur. In a telephone conversation with the vibratory hammer manufacturer, they indicated that they were not contacted prior to the incident. In this case, the manufacturer would have offered their unit or recommended what safety features should be incorporated in a remote control. 
Recommendation \# 3: Employer should ensure that workers are trained on the hazards of equipment and follow manufacturer's operating manual (e.g., bleeding entrained air from the line to prevent clamp failure).

- The manufacturer's Operation, Maintenance and Parts Manual stated that the hydraulic lines should be bled of entrained air at each set-up. None of the crew was aware of this requirement.

- It is unknown whether the vibratory hammer operating manual was reviewed or discussed during pre-task planning or when a change-in-plan occurred. A suggested practice is to highlight manufacturer's safety recommendations in the manual for review and discussion during planning or change in process.

- Hazards may be different for the various crane attachments and there may be a gap in time between each use. Therefore, the hazards, their controls and safe practices should be reviewed and communicated to the crew before each use.

\section{Recommendation \# 4: Employers should ensure that a risk assessment is conducted} whenever a change-in-plan occurs and workers should be encouraged and reinforced for reporting unsafe conditions and participating in implementation of hazard controls.

- In the initial lift, the $\mathrm{H}$-beam pile was rigged for hoisting using quick release coupler device attached to the crane and one end of the pile. It was lifted safely and placed into a drilled hole. Complete extraction of the pile did not incorporate the same rigging practices and re-drilling the hole was a last minute "change in plan." A risk assessment incorporating a discussion with the operator and crew may have identified the loss-of-load hazard.

- It is unknown whether the crane operator, crew, or qualified rigger was given the opportunity or encouraged to identify and report the potential for loss-of-load (e.g., pile not attached to the whip line or the clamp housing).

- Although the plan may have been to place the pile back into the hole after re-drilling, a hazard assessment may have considered a recurrence of the earlier problem with the drill and other unexpected factors that could have affected that plan. Safely storing the $\mathrm{H}$-beam could then have been an alternative plan and as described in the manual, to safely store the pile using the vibratory hammer, a line and shackle connecting the pile to the hammer would be needed to control lowering of the pile for safe storage.

\section{Recommendation \#5: Incident investigations should include a root cause analysis to identify hazards, recommended actions to control these hazards and follow-up procedures to ensure that these actions are implemented.}

- The previous incident investigation identified potential for clamp failure and the destructive outcome of a falling pile. The immediate cause (worn clamp jaws) was identified. Recognizing the potential for serious injuries and equipment damage, the employer should have incorporated pile safety restraint in their standard procedure.

- While the pile was held in place by the vibratory hammer clamp the crew worked within its fall zone although they were not engaged in hooking, unhooking or guiding 
the load. The previous incident should have initiated actions (training, enforcement, etc.) to ensure that employees worked outside of the fall zone.

\section{REFERENCES}

American Piledriving Equipment Inc. Operation/Maintenance Manual https://www.apevibro.com/manuals/APE/Vibratory Hammers/APE-VIBRO-150\&150T-35020060203.pdf

Bureau of Labor Statistics. 2008. Crane related occupational fatalities. Available online: http://www.bls.gov/iif/oshwc/osh/os/osh crane 2006.pdf

CPWR. 2009. Crane-related deaths in construction and recommendations for their prevention. Available online: http://www.cpwr.com/research/crane-related-deaths-construction-andrecommendations-their-prevention

International Construction Equipment (ICE) Owner's Manual Vibratory Hammers. Available online: http://www.slideshare.net/ice vibro/ice-vibratory-hammer-owners-manual

MKT Operating, Maintenance and Parts Manual. Available online: https://www.apevibro.com/manuals/MKT/MKT V-20 HP-350.pdf

New Jersey FACE. 2004. Construction Worker Struck and Killed by a Pile Falling From a Crane. Available online: http://nj.gov/health/surv/documents/03nj010.pdf

Occupational Safety and Health Administration. 2010. Cranes and Derricks in Construction Final Rule. Available online: www.osha.gov/cranes-derricks/index.html

Occupational Safety and Health Administration. 2010. OSHA Fact Sheet: Subpart CC-Cranes and Derricks in Construction: Qualified Rigger. https://www.osha.gov/Publications/cranesqualified-rigger-factsheet.pdf

Oregon OSHA. 2011. Cranes and derricks in construction: Oregon OSHA's guide to key requirements in Subdivision CC: the cranes and derricks standard. Available online:http://www.orosha.org/pdf/pubs/4927.pdf

Oregon OSHA, 2014. Interpretation letter, "Crane Operator Certification" Available online: OROSHA http://www.orosha.org/interps/2014/crane-operator-certification.pdf

Oregon OSHA, 2015. Oregon OSHA Fact Sheet: Oregon OSHA's crane standard for the construction industry. Available online:

http://www.orosha.org/pdf/pubs/fact_sheets/fs38.pdf 
Oregon OSHA, CC 1926.1425 Keeping Clear of the Load (pg 61)

http://www.orosha.org/pdf/rules/division 3/div3cc.pdf

\section{FOR MORE INFORMATION}

OR-FACE/Oregon Institute of Occupational Health Sciences, L606

Oregon Health \& Science University

3181 SW Sam Jackson Park Rd

Portland OR 97239-3098

Phone 503-494-2281

Email: orface@ohsu.edu

Website: www.ohsu.edu/xd/research/centers-institutes/oregon-institute-occupational-healthsciences/outreach/or-face/

Oregon Fatality Assessment and Control Evaluation (OR-FACE) is a project of the Oregon Institute of Occupational Health Sciences at Oregon Health \& Science University (OHSU). OR-FACE is supported by a cooperative agreement with the National Institute for Occupational Safety and Health (NIOSH) (grant \#2U60OH008472-06) through the Occupational Public Health Program (OPHP) of the Public Health Division of the Oregon Health Authority.

OR-FACE reports are for information, research, or occupational injury control only. Safety and health practices may have changed since the investigation was conducted and the report was completed. Persons needing regulatory compliance information should consult the appropriate regulatory agency. 